\title{
A qualitative text-analysis of perceptions on palliative care: Survey of student in online course for understanding cancer in Japan.
}

\section{Kiyotaka WATANABE1, Takao Tashiro2, Satoko Matsumoto3, Motohiro Matoba4. \\ 1)Teikyo University School of Medicine, Department of Internal Medicine, Tokvo. Japan.}

2)The Open University of Japan, Living and Welfare, Chiba, Japan.

3)NTT Medical Center Tokyo, Quality Indicator Section, Tokyo, Japan.

4)Aomori Prefectural Central Hospital, Aomori, Japan.

\section{Introduction:}

Cancer has been one of the main causes of death in developed countries, and palliative care should be integrated from early phase of trajectory both to patients and their families. People are becoming interested in learning about cancer.

\section{Objectives}

To verify the effectiveness of education materials that are easy to understand for citizens.

\section{Methods}

A course "Understanding Cancer in Japan," which provides web-based education was launched as part of lifelong health literacy education at the Open University of Japan since 2016. Students attending this interactive program learn about various aspects on cancer mechanism, prevention, screening, diagnosis, treatment, palliative care, cancer policies and welfare programs for 4 months. An anonymous selfadministered questionnaire survey was conducted in the lecture about palliative care, including evaluation of the course. We analyzed each record using SPSS Text Analytics for Surveys.

\section{Results}

1,521 students of the all over Japan answered the questionnaire. 1,457 (95.7\%) students replied about a lecture as beneficial. The key words were divided with a linguistic method into 30 categories: "palliative care", "patients", "medical care", "treatment" , "care", "oneself", etc. Five clusters were formed in the cluster analysis: Thoughts on introduction, social issues, quality of life, intervention, and perception.

\section{Conclusions}

Students were able to understand basic knowledge about significance of palliative care and we could grasp their image of the understanding with linguistic approach. Online course can be effective method for prevailing knowledge on palliative care and empowering attendees for advanced decision making. The feedback from students shows a utility as a educational program for citizens.

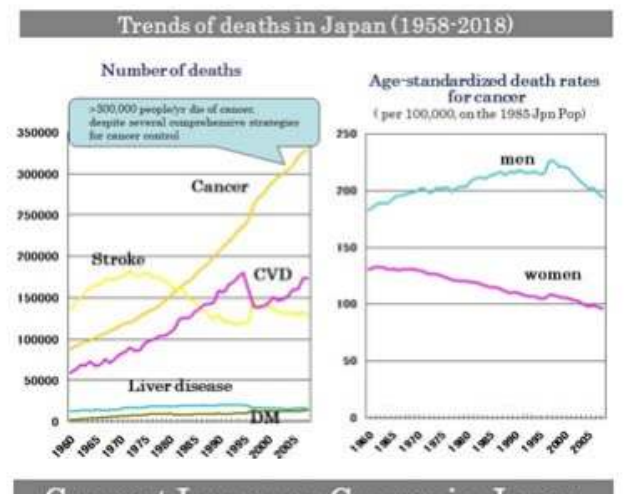

Current Issues on Cancer in Japan

- 372,986 people/yr die of cancer(2016),

- 862,452 newly diagnosed (2013),

- Lifetime Risk: $62 \%$ (Men), 46\%(Women)

- Medical cost Y4.12trillion (37.4billion)/year(2017) (13.7\% of medical cost)

Demand for cancer information - People feel deficient in information on cancer care

Imbalance in cancer care quality - Inequity in medical care by institution and residential area - Insufficient understanding of comprehensive care approach - Insufficient infrastructure for palliative care, care at home and end-stage care

Online Education Course "Understanding Cancer in Japan."

- 15 topics, semi-annually since 2016

- E-learning, Q\&As, discussions, reports, and certification test

- 1st track: introduction, cancer research, prevention and screening

- 2nd track: breast/lung/colorectal cancer, palliative care, home care

- 3rd track: radiation, chemotherapy, cancer control, patient advocacy

- E-mail newsletter provides latest topics, relevant cancer information and tips about final report

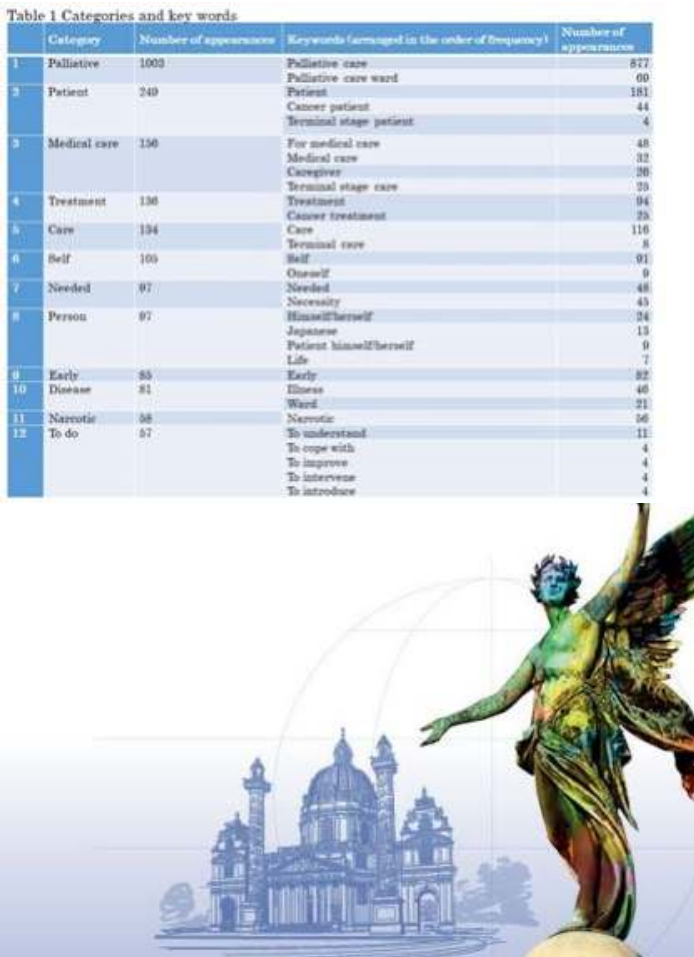

